\title{
Nrf2-Mediated Expansion of Pilosebaceous Cells Accelerates Cutaneous Wound Healing
}

Sukalp Muzumdar, ${ }^{*}$ Hayley Hiebert, ${ }^{*}$ Eric Haertel, ${ }^{*}$ Maya Ben-Yehuda Greenwald, ${ }^{*}$ Wilhelm Bloch, ${ }^{\dagger}$ Sabine Werner, ${ }^{*}$ and Matthias Schäfer*

From the Department of Biology,* Institute of Molecular Health Sciences, ETH Zurich, Zurich, Switzerland; and the Department of Molecular and Cellular Sport Medicine, ${ }^{\dagger}$ German Sport University Cologne, Cologne, Germany

Accepted for publication November 19, 2018.

Address correspondence to Matthias Schäfer, PD Dr. Department of Biology, Institute of Molecular Health Sciences, ETH Zurich, OttoStern-Weg 7, 8093 Zurich, Switzerland. E-mail: matthias. schaefer@biol.ethz.ch.

\begin{abstract}
The nuclear factor (erythroid-derived 2)-like 2 (Nrf2) transcription factor is a key regulator of the cellular stress response. Therefore, pharmacologic Nrf2 activation is a promising strategy for skin protection and cancer prevention. This study found that genetic Nrf2 activation in keratinocytes accelerates wound repair. Enhanced proliferation of cells of the pilosebaceous unit peripheral to the wound and a concomitant acceleration of re-epithelialization were identified as the underlying mechanism. Nrf2 specifically promoted the expansion of pilosebaceous cells expressing markers of junctional zone and upper isthmus follicular stem cells. This may result, at least in part, from the upregulation of the direct Nrf2 target epigen and a concomitant increase in epidermal growth factor receptor signaling. The increase in pilosebaceous cells provided a larger pool of keratinocytes that migrate into the wound, resulting in faster wound closure. These results unravel a novel function of Nrf2 in wound repair and suggest the use of NRF2-activating compounds in patients with impaired healing. (Am J Pathol 2019, 189: 568-579; https://doi.org/10.1016/j.ajpath.2018.11.017)
\end{abstract}

Nuclear factor (erythroid-derived 2)-like 2 (NFE2L2; Nrf2) is a member of the cap'n' collar family of transcription factors. It plays a central role in cellular antioxidant defense and in compound detoxification by controlling the expression of genes encoding phase II enzymes, various antioxidant proteins, and transporters. In the murine and human epidermis, Nrf2 forms a basal-to-suprabasal transcription and activity gradient, which protects differentiated keratinocytes from oxidative damage by exogenous insults (eg, UV light and toxicants). ${ }^{1,2}$ Pharmacologic Nrf2 activation protects keratinocytes from the toxicity of chemicals (eg, arsenite, cumene hydroperoxide, and sulfur mustard analogs $)^{3}$ as well as from UVB-induced apoptosis and skin tumor formation. $^{4-6}$ The strong promotion of reactive oxygen species (ROS) and xenobiotic detoxification by Nrf2 makes this transcription factor an attractive target for skin protection, especially under stress conditions.

In response to skin injury in mice, Nrf2 mRNA levels increase in the hyperproliferative wound epithelium. ${ }^{7}$ This increase is likely of functional importance because keratinocytes are exposed to high levels of ROS on wounding.
Immediately after wounding of different lower organisms and most likely also of mammals, epithelial cells themselves release ROS. ${ }^{8-10}$ Later, migrating keratinocytes are exposed to ROS produced by neutrophils and macrophages. ${ }^{11-13}$ ROS are essential for the prevention of wound infections, and they initiate critical signaling cascades in keratinocytes, which activate migration and proliferation of these cells at the wound edge. ${ }^{11}$ Excessive levels of ROS, however, which are present in nonhealing ulcers, are known to induce apoptosis and to inhibit keratinocyte migration and proliferation. $^{14,15}$ Surprisingly, Nrf2 knockout mice and transgenic mice expressing a dominant-negative Nrf2 mutant in keratinocytes showed normal reepithelialization and wound closure rates. ${ }^{7,16}$ However, in a streptozotocin-induced diabetic wound model, loss of Nrf2 further delayed the reepithelialization process due to enhanced oxidative

Supported by Gebert-Rüf Foundation grant GRS-052/13 (M.S. and S.W.) and the Swiss National Science Foundation grants 310030-132884 (S.W.) and 31003A_169204 (S.W.).

Disclosures: None declared. 
Table 1 List of Quantitative RT-PCR and Genotyping Primers Used in This Study

\begin{tabular}{|c|c|c|}
\hline Primer & Forward primer & Reverse primer \\
\hline \multicolumn{3}{|c|}{ Quantitative RT-PCR } \\
\hline Epgn & $5^{\prime}-\mathrm{ATGAGCTGAAGCAAGCCATT-3^{ \prime }}$ & $5^{\prime}-$ CTCCCTCCAGAGCAGATGAT-3' \\
\hline Gsta3 & $5^{\prime}-$ TACTTTGATGGCAGGGGAAG-3' & 5'-GCACTTGCTGGAACATCAGA-3' \\
\hline Nqo1 & $5^{\prime}-$ CTGGCCCATTCAGAGAAGAC- $3^{\prime}$ & 5'-GTCTGCAGCTTCCAGCTTCT-3' \\
\hline Nrf2 & $5^{\prime}$-CCAGCTACTCCCAGGTTGC-3' & 5'-CСАААCTTGCTCСАTGTCCT-3' \\
\hline caNrf2 & 5'-CGGCTCAGCACCTTGTATC-3' & $5^{\prime}$-СTTATTCCAAGCGGCTTCGGC-3' \\
\hline K5cre & 5'-AACATGCTTCATCGTCGG-3' & 5'-TTCGGATCATCAGCTACACC-3' \\
\hline Myogenin & 5'-AACATGCTTCATCGTCGG-3' & $5^{\prime}-\mathrm{TTCGGATCATCAGCTACACC-3^{ \prime }}$ \\
\hline
\end{tabular}

damage and increased apoptosis, as well as low transforming growth factor- $\beta 1$ and high matrix metalloproteinase 9 expression levels. ${ }^{17}$ Thus, Nrf 2 seems to be necessary for efficient protection of keratinocytes under situations of impaired healing, where ROS levels are significantly increased. Nrf2 activity in the wounds of diabetic mice is apparently insufficient as reflected by the enhanced wound healing upon treatment with the Nrf2-activating compound sulforaphane $^{17}$ or on knockdown of the Nrf2 antagonist Keap1 at the wound site. ${ }^{18,19}$ However, it remains to be determined whether this beneficial effect results from Nrf2 activation in keratinocytes and/or in other cell types of the wound.

To study the consequences of keratinocyte-specific Nrf2 activation in vivo, we previously generated transgenic mice expressing a constitutively active (ca) Nrf2 mutant under control of the $\beta$-actin promoter. ${ }^{1,20}$ Keratinocyte-specific expression was achieved by inserting a floxed STOP cassette upstream of the caNrf2 transgene and by crossing these mice with transgenic mice expressing Cre recombinase under control of the keratin 5 (K5) promoter. In K5cre-caNrf2 mice, UVB-induced keratinocyte apoptosis was reduced because of enhanced ROS detoxification. In addition, these mice had mild hyperkeratosis in the tail skin. ${ }^{1,21}$ K5cre-CMVcaNrf2 mice, which exhibit higher expression of the caNrf2 transgene due to the insertion of a cytomegalovirus enhancer upstream of the $\beta$-actin promoter, developed acanthosis, hyperkeratosis, epidermal barrier disturbance, and chronic, mild cutaneous inflammation. ${ }^{20}$ In this study, we report a novel wound healing-promoting effect of Nrf2 activation through expansion of cells in the pilosebaceous unit.

\section{Material and Methods}

\section{Animal Experiments}

Mice were kept under specific pathogen-free conditions and received water and food ad libitum. Mouse maintenance and experiments had been approved by the

Table 2 Antibodies for Immunofluorescence and Immunohistochemistry

\begin{tabular}{llll}
\hline Antibody & Host & Dilution & Source \\
\hline Primary antibody (anti-) & & & \\
CD3 & Rabbit & $1: 100$ & Dako, Glostrup, Denmark \\
Cleaved caspase-3 & Rabbit & $1: 100$ & Cell Signaling, Danvers, MA \\
Keratin 6 & Rabbit & $1: 1000$ & Covance, Princeton, NJ \\
Keratin 10 & Rabbit & $1: 500$ & Covance \\
Keratin 15 & Mouse & $1: 1000$ & LHK15, Thermo Fisher Scientific, Waltham, MA \\
Loricrin & Rabbit & $1: 250$ & Covance \\
Lrig1 & Goat & $1: 200$ & R\&D Systems, Minneapolis, MN \\
Ly6G & Rat & $1: 100$ & BD Biosciences, Franklin Lakes, NJ \\
CD68-biotin & Rat & $1: 200$ & Serotec (now BioRad), Puchheim, Germany \\
Proliferating cell nuclear antigen & Rabbit & $1: 1000$ & Santa Cruz Biotechnology, Santa Cruz, CA \\
Plet1 & Rat & $1: 200$ & Nordic MUbio, Susteren, The Netherlands \\
Sprr2 & Rabbit & $1: 200$ & Kindly provided by Daniel Hohl, University Hospital \\
& & & Lausanne, Switzerland \\
Secondary antibody & & \\
Anti-rabbit biotin & Goat & $1: 500$ & Jackson ImmunoResearch, Suffolk, United Kingdom \\
Anti-rabbit Cy3 & Goat & $1: 250$ & \\
Anti-rat biotin & Rabbit & $1: 250$ & Vector Laboratories, Burlingame, CA \\
Anti-goat Cy3 & Cow & $1: 250$ & Jackson ImmunoResearch, Suffolk, UK \\
\hline
\end{tabular}


Table 3 Antibodies Used for Flow Cytometry Analysis

\begin{tabular}{ll}
\hline Antibody & Source \\
\hline$\alpha_{6}$-Integrin-biotin/streptavidin-Brilliant Violet 711 & BioLegend (313604), San Diego, CA, and BD Biosciences (563262), \\
& Franklin Lake, NJ \\
CD34-AlexaFluor 647 & BD Biosciences (560233) \\
CD45-Pacific Blue & BioLegend (103216) \\
Sca-1-PE-Cy7 & BioLegend (122514) \\
Ki-67-PE & BioLegend (652403) \\
Fc block & BD Biosciences (553142) \\
\hline
\end{tabular}

Cy7, cyanine 7; PE, phosphatidylethanolamine.

veterinary authorities of Zurich, Switzerland. K5crecaNrf2 and K5cre-CMVcaNrf2 (tg/tg) mice, K5-Cre control (tg/wt) mice, and their genotyping were previously described. ${ }^{1,20}$ Primer sequences are given in Table 1. For the analysis of the wound healing process, 8- to 11-week-old female mice were anesthetized by i.p. injection of $8 \mathrm{~g} / \mathrm{L}$ of xylazine and $10 \mathrm{~g} / \mathrm{L}$ of ketamine (Streuli Pharma AG, Uznach, Switzerland). Two anterior and two posterior wounds were generated on both sides of the back lateral to the spine using a 5-mm hole punch (Stiefel, Brentford, UK). Only mice with hair follicles (HFs) in the telogen phase were wounded and analyzed. Wound biopsy specimens were taken after euthanasia (carbon dioxide inhalation). Removal of the suprabasal layers of the epidermis was performed by tape stripping, using Tesa extra Power Perfect tape (Tesa Tape Schweiz AG, Bergdietikon, Switzerland). The number of strips of tape used varied between genotypes, with the tg/wt mice requiring 15 strips of tape each and the $\mathrm{tg} / \mathrm{tg}$ mice requiring 25 separate strips of tape, owing to the hyperkeratosis and acanthosis in the latter. Complete removal of the differentiated layers under the chosen conditions was confirmed by hematoxylin and eosin (H\&E) staining of skin sections. Measurement of transepidermal water loss (TEWL) and separation of the epidermis from the underlying tissue were previously described. ${ }^{20,22}$

\section{Morphometric Analysis}

H\&E-stained, 7- $\mu \mathrm{m}$ paraffin sections of murine excisional wound and tape-stripped skin samples were digitally imaged. Length, area, and cell numbers of the wound epithelium, the hyperthickened epithelium at the wound edge and the HFs, as well as the distance between the wound edges (wound diameter) and the wound gap were analyzed by histomorphometry. The thickness of the epidermis and of the HFs was expressed as a ratio of length to area. Wound closure was calculated as ratio of the length of the wound epithelium to the wound diameter. From tape-stripped skin, the length of the wound epithelium, cell number, and distance between HFs were analyzed. Morphometric analyses were performed using Open Lab software version 3.5.1 (Improvision/Perkin Elmer, Waltham, MA).

\section{RNA Isolation and Quantitative RT-PCR Analysis}

RNA isolation and purification were performed with the MinElute kit (Qiagen, Hilden, Germany). cDNA synthesis and quantitative RT-PCR (RT-qPCR) were described previously. ${ }^{20}$ RT-qPCR primer sequences are provided in Table 1.

\section{Cell Culture}

Murine immortalized keratinocytes were cultured in defined keratinocyte-serum free medium (Life Technologies, Zug, Switzerland). Murine immortalized keratinocytes were treated with $50 \mu \mathrm{mol} / \mathrm{L}$ tert-butylhydroquinone (Sigma, Buchs, Switzerland) or vehicle overnight.

\section{Histologic and Immunohistologic Techniques}

H\&E, immunofluorescence, immunohistochemistry, and toluidine blue staining procedures were previously described. ${ }^{1}$ Primary and secondary antibodies are listed in Table 2. Micrographs from H\&E-stained and immunohistochemistry-stained sections were obtained using a Zeiss Axioskop 2 microscope with an Axiocam $\mathrm{HRc}$ camera; immunofluorescence images were photographed using a Zeiss Axio Imager.A1 microscope with an Axiocam MRm camera, both with the Axiovision software AxioVs40 version 4.8.2.0 (Zeiss, Oberkochen, Germany). Immune cells in the entire granulation tissue were quantified using the stained sections, and data are provided as cell counts. ${ }^{2}$ Electron microscopy was performed as recently described $^{23}$ using an EM109 electron microscope (Zeiss).

\section{Flow Cytometry}

Mice were euthanized by carbon dioxide inhalation and subsequently shaved before harvesting the skin. After removal of the subcutaneous fat, the skin was incubated in 3 units $/ \mathrm{mL}$ of dispase for 45 minutes at $37^{\circ} \mathrm{C}$ with shaking to separate the epidermis. The epidermis was then treated for 20 minutes at room temperature with with $0.2 \mathrm{mg} / \mathrm{mL}$ of DNAse $(\geq 400 \mathrm{Kunitz} / \mathrm{mg}$ protein) in the presence of $20 \mu \mathrm{mol} / \mathrm{L}$ magnesium chloride. EGTA and EDTA were then added to a final concentration of $7.5 \mathrm{mmol} / \mathrm{L}$ to complete tissue dissociation. After straining the cells through a $70-\mu \mathrm{m}$ cell strainer 


\section{Wild-type mice}

A

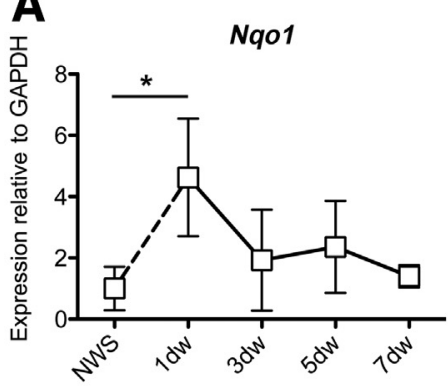

B

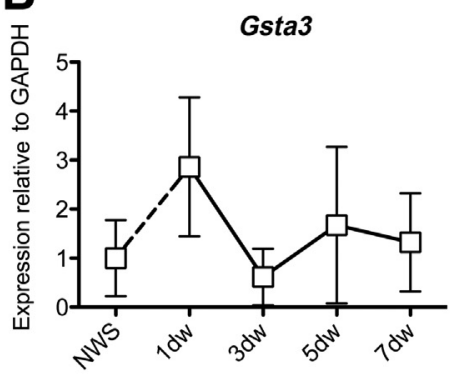

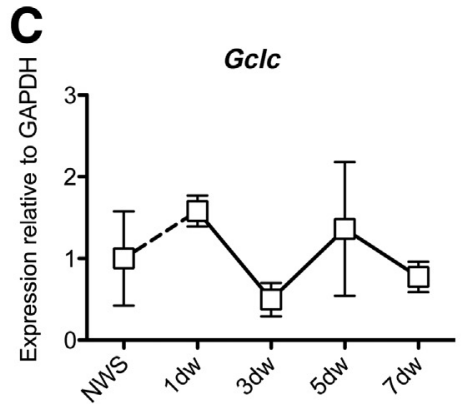

\section{K5cre-CMVcaNrf2 mice}

\section{D}

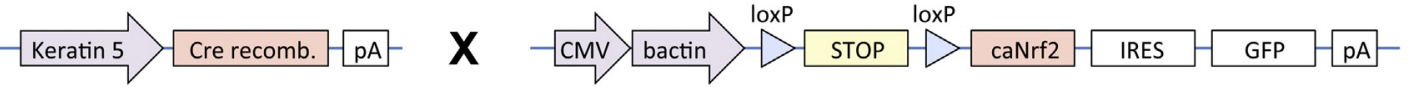

E

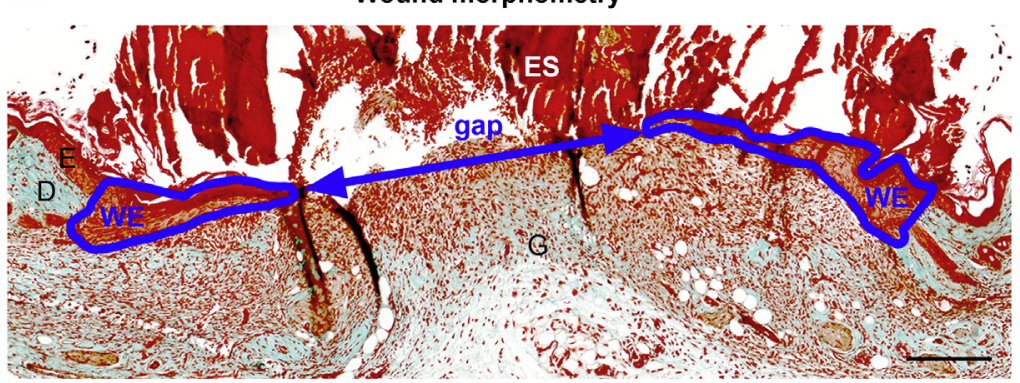

G

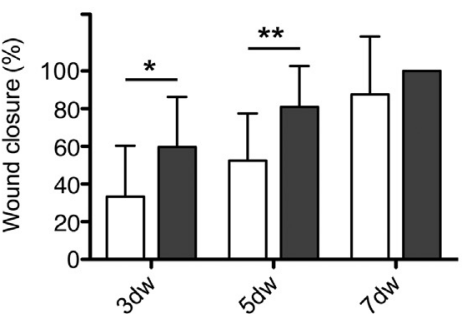

J

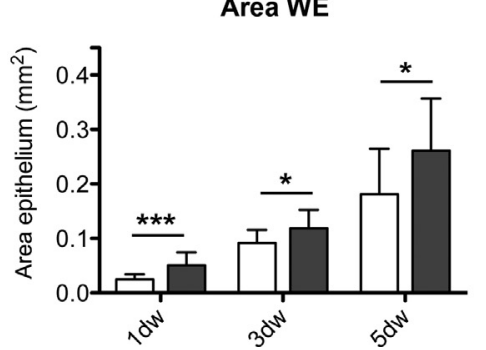

H
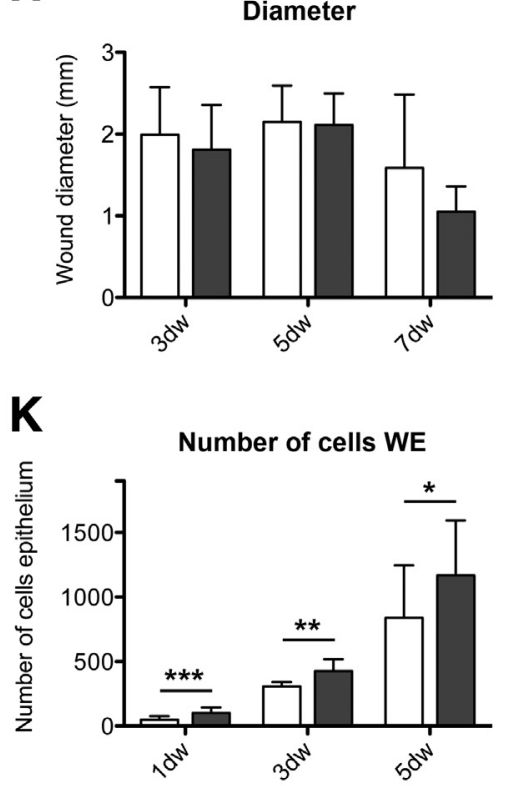

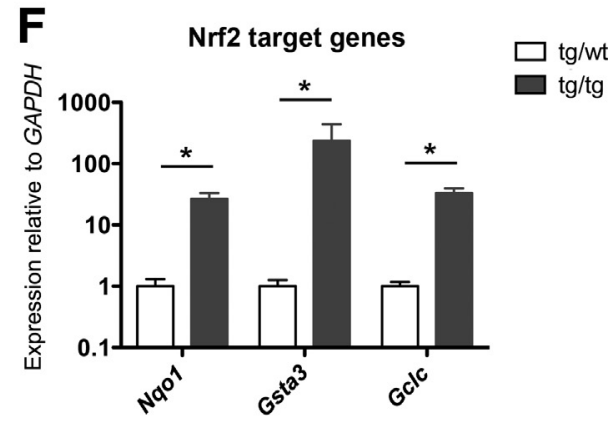

I

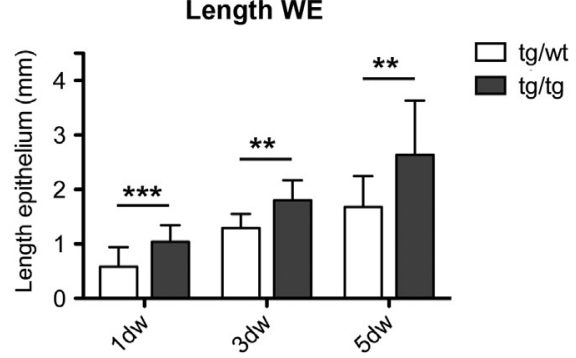

L

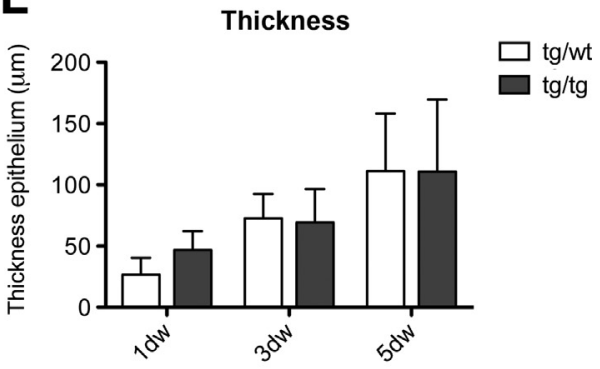

Figure 1 Accelerated wound healing in K5cre-CMVcaNrf2 mice. A-C: Expression of Nqo1 (A), Gsta3 (B), and Gclc (C) in the epidermis of nonwounded back skin and in the wound epithelium of wild-type mice. D: Schematic representation of the strategy used for the generation of K5cre-CMVcaNrf2 mice. E: Masson Trichrome stain of a section from a representative 5-day wound (5dw). Blue lines demarcate the wound epithelium (WE), and the double-headed arrow indicates the open wound (gap). F: Expression of Nq01, Gsta3, and Gclc in the WE of $5 \mathrm{dw}$ of tg/wt and tg/tg mice. G-L: Wound closure (G) and wound diameter $(\mathbf{H})$ of $3 \mathrm{dw}, 5 \mathrm{dw}$, and $7 \mathrm{dw}$ and length $(\mathbf{I})$, area $(\mathbf{J})$, cell number $(\mathbf{K})$, and thickness $(\mathbf{L})$ of the WE of $1 \mathrm{dw}$, $3 \mathrm{dw}$, and $5 \mathrm{dw}$ of $\mathrm{tg} / \mathrm{wt}$ and $\mathrm{tg} / \mathrm{tg} \mathrm{mice} . n=4 \mathrm{to} 6$ mice $(\mathbf{F}) ; n=5$ to 11 mice $(\mathbf{G}-\mathbf{L}) ; n=9$ to 21 wounds $(\mathbf{G}-\mathbf{L})$. ${ }^{*} P \leq 0.05$, ${ }^{* *} P \leq 0.01$, and ${ }^{* * *} P \leq 0.001$ (U-test). Scale bar $=200 \mu \mathrm{m}$. $\mathrm{D}$, dermis; $\mathrm{E}$, epidermis; ES, eschar; G, granulation tissue; GAPDH, glyceraldehyde-3-phosphate dehydrogenase; recomb., recombinase; NWS, nonwounded skin. 


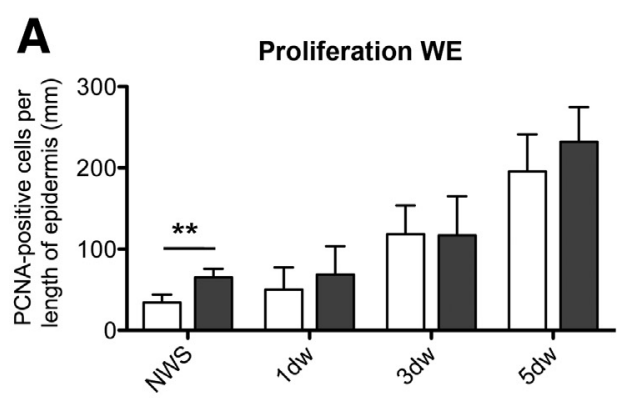

B
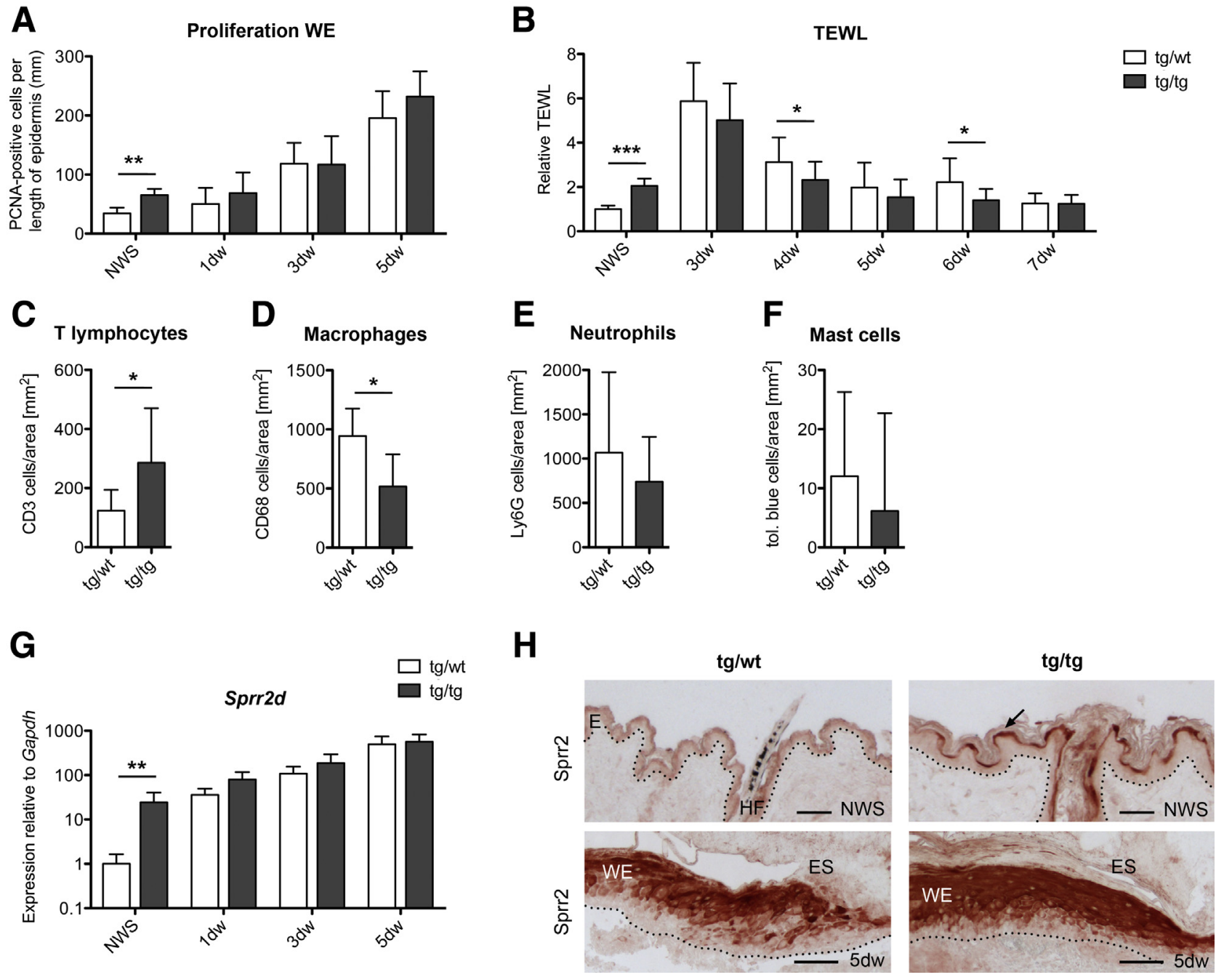

Figure 2 Analysis of the wound epithelium in K5cre-CMVcaNrf2 mice. A: Proliferating cell nuclear antigen (PCNA)-positive cells per length of epidermis in nonwounded skin (NWS) or in the wound epithelium (WE) of 1-day wound (1dw), 3dw, and 5dw of tg/wt and tg/tg mice. B: Transepidermal water loss (TEWL) of NWS and 3dw, 4dw, 5dw, 6dw, and 7dw of tg/wt and $\mathrm{tg} / \mathrm{tg}$ mice. C-F: Number of CD3-positive T cells (C), CD68-positive macrophages (D), Ly-6G-positive neutrophils (E), and toluidine blue-stained mast cells $(\mathbf{F})$ per square millimeter of granulation tissue in $\mathrm{tg} / \mathrm{wt}$ and $\mathrm{tg} / \mathrm{tg}$ mice. G: Quantitative RT-PCR analysis of Sprr2d relative to Gapdh using RNA from the epidermis of NWS and $1 \mathrm{dw}, 3 \mathrm{dw}$, and $5 \mathrm{dw}$ of $\mathrm{tg} / \mathrm{wt}$ and $\mathrm{tg} / \mathrm{tg}$ mice. Mean values of nonwounded epidermis of $\mathrm{tg} / \mathrm{wt}$ mice were arbitrarily set to 1. H: Immunohistochemistry for Sprr2 using sections of $\mathrm{tg} / \mathrm{wt}$ and $\mathrm{tg} / \mathrm{tg}$ NWS (upper) and $5 \mathrm{dw}$ epithelium (lower). Dotted lines demarcate the basement membrane. The arrow indicates strong expression of Sprr2d in differentiated keratinocytes of $\mathrm{tg} / \mathrm{tg}$ mice. $n=5$ to 6 mice and 7 to 11 wounds (A); $n=4$ to 5 mice and 8 to 10 wounds $(\mathbf{B}) ; n=5$ to 7 mice $(\mathbf{C}-\mathbf{F}) ; n=5$ to 14 wounds $(\mathbf{C}-\mathbf{F}) ; n=4$ to 7 mice $(\mathbf{G})$. ${ }^{*} P \leq 0.05,{ }^{* *} P \leq 0.01$, and ${ }^{* *} P \leq 0.001$ (U-test). Scale bars $=50 \mu \mathrm{m}$. E, epidermis; ES, eschar; HF, hair follicle; NWS, nonwounded skin; WE, wound epithelium.

(CellTrics, Sysmex Europe GmbH, Norstedt, Germany), cell surface labeling, including a live/dead marker, was performed for 20 minutes at $4^{\circ} \mathrm{C}$. The live/dead marker was then neutralized by addition of and washing with flow buffer that contained bovine serum albumin. Intracellular antigen labeling for flow cytometry was performed for 45 minutes at $4^{\circ} \mathrm{C}$ after fixation and permeabilization of the cells (FoxP3 kit; eBioscience/ThermoFisher, Zug, Switzerland). Cells were washed again and resuspended in flow buffer prior to flow cytometry. Single-stained beads or cells were used to set up a compensation matrix on the flow cytometer. Postcytometry analysis was performed using FlowJo version 10 (FlowJo, Ashland, OR). Antibodies used are listed in Table 3.

\section{Scratch and Transwell Assays}

Confluent primary murine keratinocytes from $\mathrm{tg} / \mathrm{wt}$ or $\mathrm{tg} / \mathrm{tg}$ mice or immortalized murine keratinocytes, which had been treated overnight with $5 \mu \mathrm{mol} / \mathrm{L}$ sulforaphane or vehicle control, were scratch wounded with a $200-\mu \mathrm{L}$ pipet tip. Scratch closure was estimated based on the number of viable cells inside the scratched area 0,18 , and 96 hours (for the primary keratinocytes) or 0,8 , and 24 hours (for the immortalized murine keratinocytes) after scratch wounding.

A transwell migration assay was performed using overnight sulforaphane- or vehicle-treated immortalized murine 
A
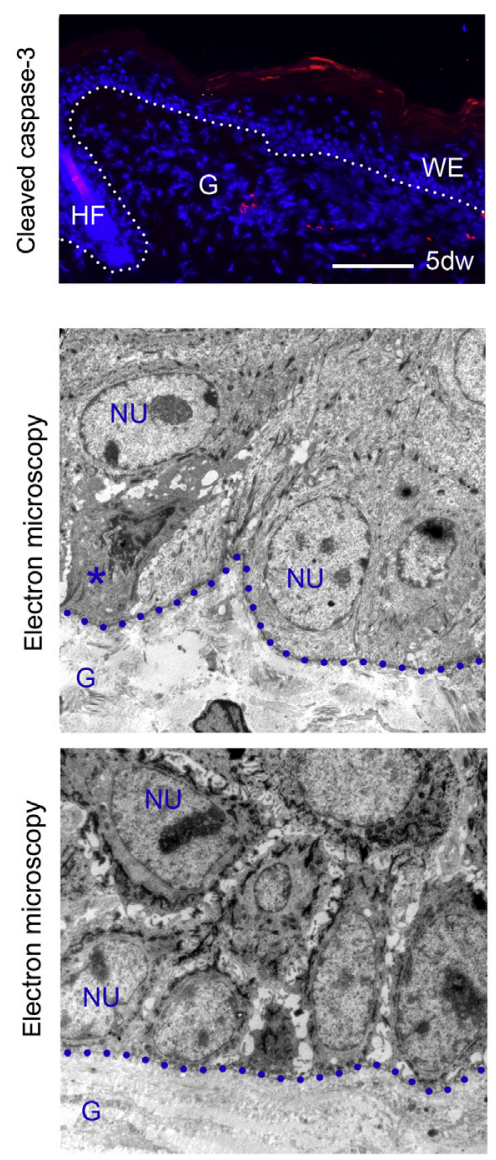

E

Transwell assay

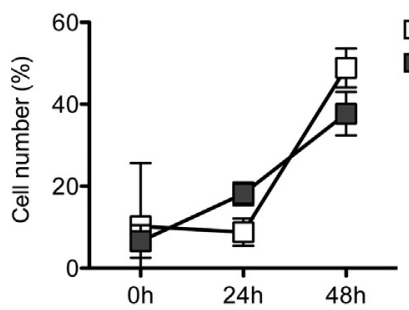

$\operatorname{tg} / \mathrm{tg}$
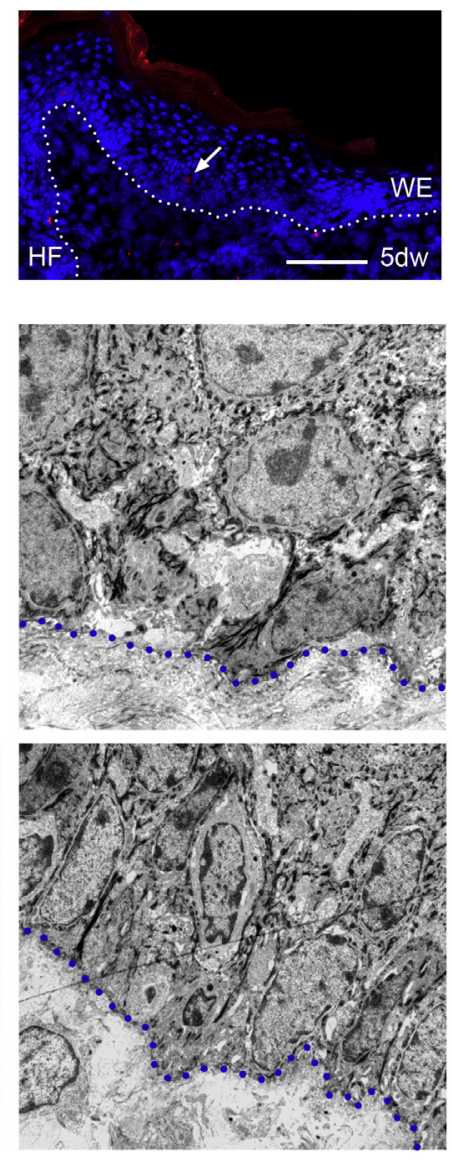

F

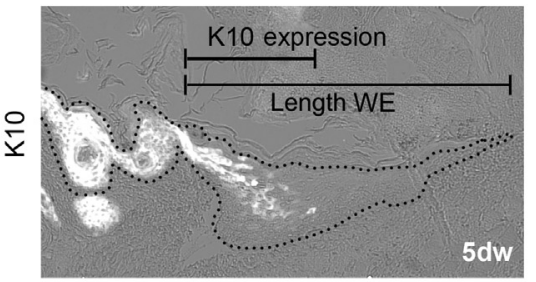

C

D
B
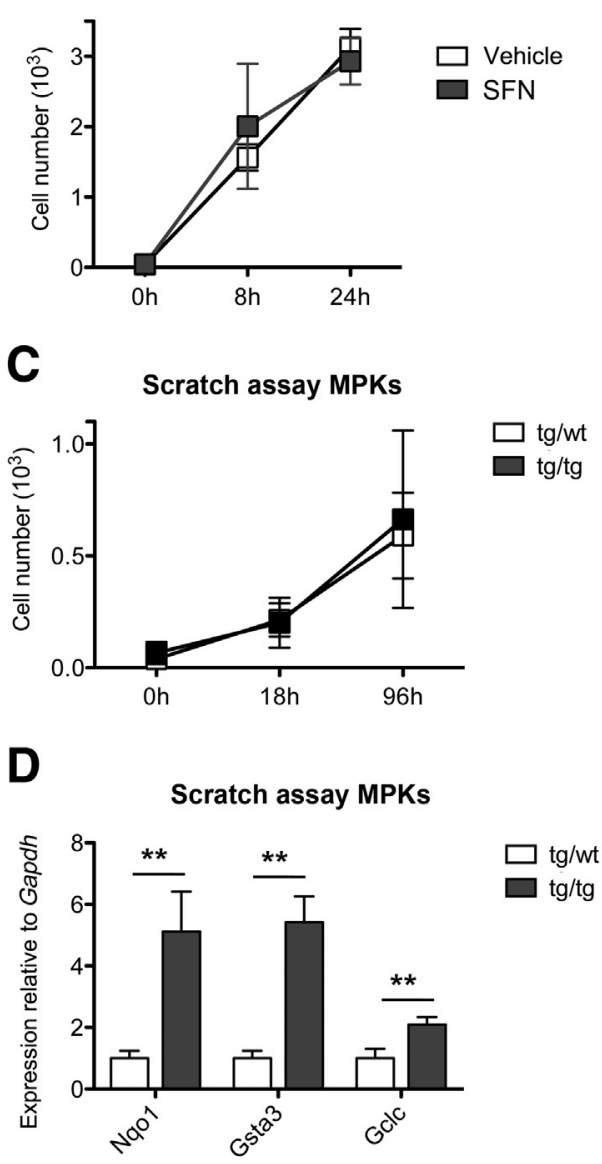

G

K10

H Loricrin

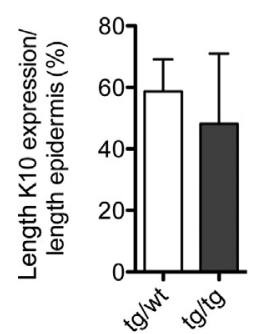

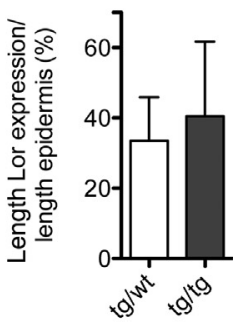

Figure 3 Nuclear factor (erythroid-derived 2)-like 2 (Nrf2) activation in keratinocytes does not affect keratinocyte apoptosis, migration, or differentiation. A: Immunofluorescence for cleaved caspase-3 using sections of 5-day wounds ( $5 \mathrm{dw}$ ) from $\mathrm{tg} / \mathrm{wt} \mathrm{and} \mathrm{tg} / \mathrm{tg}$ mice. Arrow indicates a cleaved caspase-3-positive cell (top row). Electron microscopy of the wound epithelium (WE) of $\mathrm{tg} / \mathrm{wt}$ and $\mathrm{tg} / \mathrm{tg}$ mice at day 3 (middle row) and day 5 (bottom row) after wounding. Note the irregular distribution of keratinocytes in the $\mathrm{tg} / \mathrm{tg}$ compared with the $\mathrm{tg} / \mathrm{wt}$ wound epithelium. Asterisk indicates apoptotic cell with shrunken and dark nucleus. The dotted lines demarcate the basement membrane. B: Scratch assay: number of viable murine immortalized keratinocytes (MIKs) within the scratched area at 0 , 8 , and 24 hours after wounding on treatment with vehicle or $5 \mu \mathrm{mol} / \mathrm{L}$ sulforaphane (SFN). C: Number of cells within the scratch at 0, 18, and 96 hours after scratch wounding of a monolayer formed by murine primary keratinocytes (MPKs) from $\mathrm{tg} / \mathrm{wt}$ and $\mathrm{tg} / \mathrm{tg}$ mice. D: Quantitative RT-PCR analysis for Nqo1, Gsta3, and Gsta3 relative to Gapdh using RNA from murine primary keratinocytes treated with vehicle or $5 \mu \mathrm{mol} / \mathrm{LSFN}$. Mean values of nonwounded epidermis were arbitrarily set to 1 . E: Transwell assay: Percentage of migrated IMKs relative to the total number at 0,24, and 48 hours after seeding of cells and treatment with vehicle or $5 \mu$ mol/LSFN. F-H: Representative image of keratin 10 expression in $5 \mathrm{dw}(\mathbf{F})$ and percentage of the area of wound epithelium positive for keratin 10 (K10) (G) and loricrin (H) in $\mathrm{tg} / \mathrm{wt}$ and $\mathrm{tg} / \mathrm{tg}$ mice. The dotted line demarcates the basement membrane. $n=6$ wells (B and $\mathbf{D}) ; n=7$ to 13 wells $(\mathbf{C}) ; n=4$ wells $(\mathbf{E}) ; n=10$ (G); $n=4$ to 8 (H). ${ }^{* * P} \leq 0.01$ (U-test). Scale bar $=50 \mu \mathrm{m} . \mathrm{G}$, granulation tissue; HF, hair follicle; NU, nucleus.

keratinocytes seeded onto tissue culture-treated polycarbonate inserts $(8-\mu \mathrm{m}$ pore size) for 24-well plates (Corning Inc., Corning, NY). Cells on the inserts were fixed with $4 \%$ paraformaldehyde for 20 minutes at 20 minutes and
24, 30, and 48 hours after seeding. They were then stained with Hoechst (1:1000), and cells on both sides of the membrane were counted using OpenLab software version 3.5.1 (Perkin Elmer, Schwerzenbach, Switzerland). 


\section{Full-thickness excisional wounds}

A

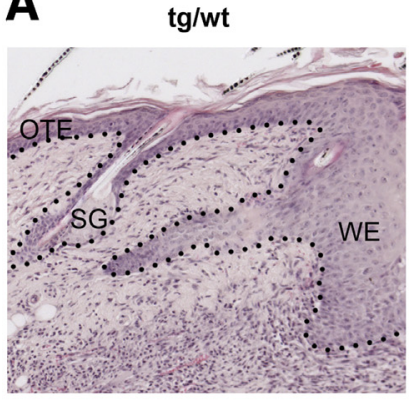

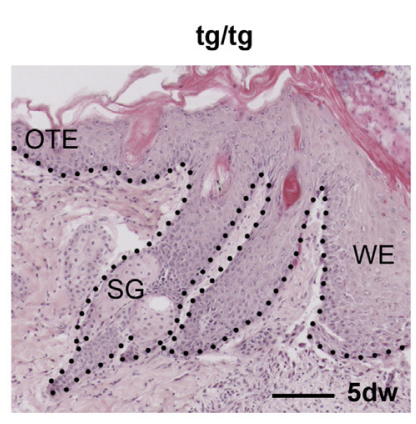

B

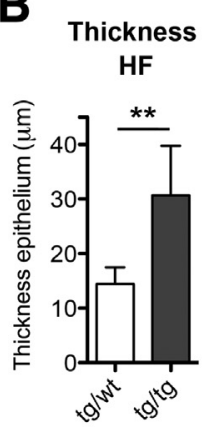

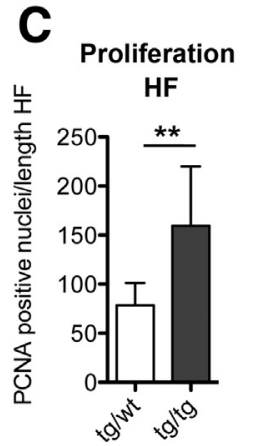

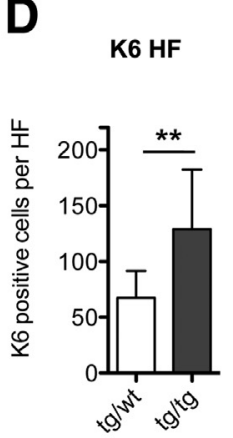

\section{Skin abrasion}
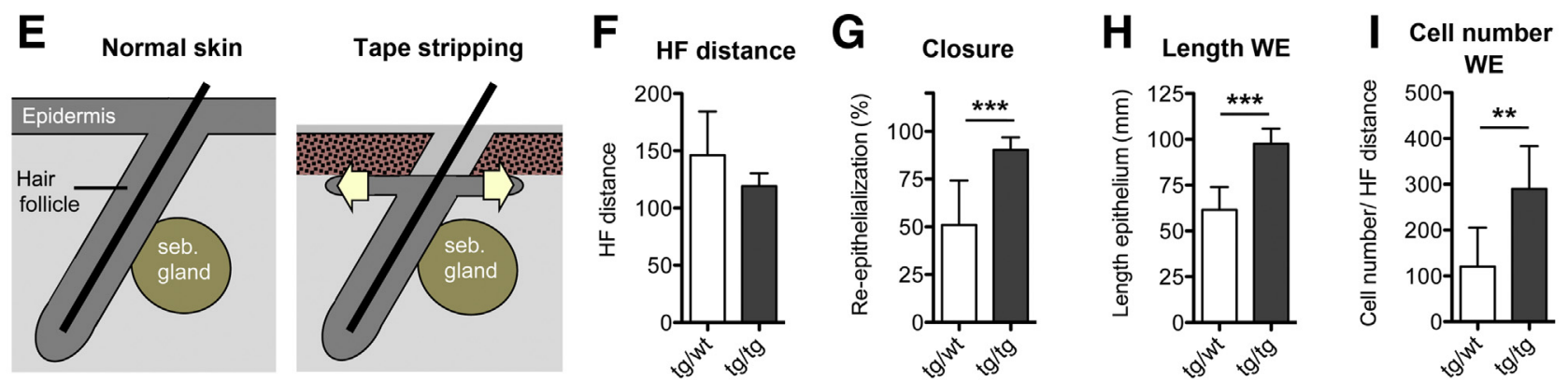

Figure 4 Cells of the pilosebaceous unit contribute to the faster healing of wounds in K5cre-CMVcaNrf2 mice. A: Hematoxylin and eosin-stained sections showing skin of $\mathrm{tg} / \mathrm{wt}$ and $\mathrm{tg} / \mathrm{tg}$ mice peripheral to full-thickness excisional 5-day wound. The dotted lines demarcate the basement membrane. B-D: Thickness of hair follicles (B), number of proliferating cell nuclear antigen (PCNA)-positive cells (C), and number of keratin 6 (K6)-positive cells (D) per length of hair follicles (HFs) at the wound margin in $\mathrm{tg} / \mathrm{wt}$ and $\mathrm{tg} / \mathrm{tg}$ mice. E: Schematic representation of reepithelialization after tape stripping. Wound epithelium (WE) is formed underneath the scab by HF keratinocytes. F-I: HF distance (F), wound closure (G), length of wound epithelium (H), and cell number in the wound epithelium (I) in tg/wt and tg/tg mice. $n=6(\mathbf{C}) ; n=7$ to 12 (D); $n=7$ to 8 (F-I). ${ }^{* *} P \leq 0.01,{ }^{* * *} P \leq 0.001$ (U-test). Scale bar $=100 \mu \mathrm{m}$. OTE, outer thickened epithelium; seb., sebaceous; SG, sebaceous gland.

\section{Statistical Analysis}

Statistical analyses were performed using the nonparametric $U$-test for non-Gaussian distribution and Prism software version 5 (GraphPad Software, La Jolla, CA). $P<0.05$ was considered statistically significant.

\section{Results}

\section{Healing of Full-Thickness Excisional Wounds Is Accelerated in $\mathrm{K} 5 \mathrm{cre}-\mathrm{CMV}$ caNrf2 Mice}

To gain insight into a potential role of $\mathrm{Nrf} 2$ in wound reepithelialization, the expression of the classic Nrf2 target genes Nqol, Gsta3, and Gclc was analyzed in the normal and wounded epidermis of wild-type mice. There was a mild increase in the expression of these genes at day 1 after wounding, followed by a decrease to basal levels at day 3 (Figure 1, A-C). This mild and transient Nrf2 activation suggests that further activation of Nrf2 in keratinocytes might be beneficial.

K5cre-caNrf2 or K5cre-CMVcaNrf2 mice, which exhibit mild or strong Nrf2 activation in keratinocytes comparable to the activity levels achieved on pharmacologic activation of endogenous Nrf2, were used
(Supplemental Figure S1A and Figure 1D). ${ }^{1,20}$ K5crecaNrf2 (tg/tg) mice had a mild but significant up-regulation of Nrf2 target genes in the epidermis. ${ }^{20}$ However, no alterations in the rate of wound closure or wound diameter or in the area and length of the wound epithelium (Figure 1E) were observed in 5-day wounds of these mice compared with $\mathrm{K} 5 \mathrm{cre}$ (control; tg/wt) mice (Supplemental Figure S1, B-F).

K5cre-CMVcaNrf2 mice, which express higher levels of the transgene, had a much stronger up-regulation of $\mathrm{Nqol}$, Gclc, and Gsta3 in the nonwounded epidermis compared to K5cre-caNrf2 mice, ${ }^{20}$ and in the wound epithelium at day 5 after full-thickness excisional wounding (Figure 1F). Remarkably, wound closure was significantly accelerated in these mice (Figure 1G). An increase in wound contraction was ruled out because the wound diameter-as measured by the distance between the wound edges - was similar in open wounds of control and transgenic mice (Figure 1H). Instead, a longer wound epithelium was observed, which exhibited an increased area and cell number; however, its mean thickness was not increased (Figure 1, I-L). These data indicate that strong Nrf2 activation in keratinocytes accelerates wound reepithelialization and wound closure through formation of a longer wound epithelium. 

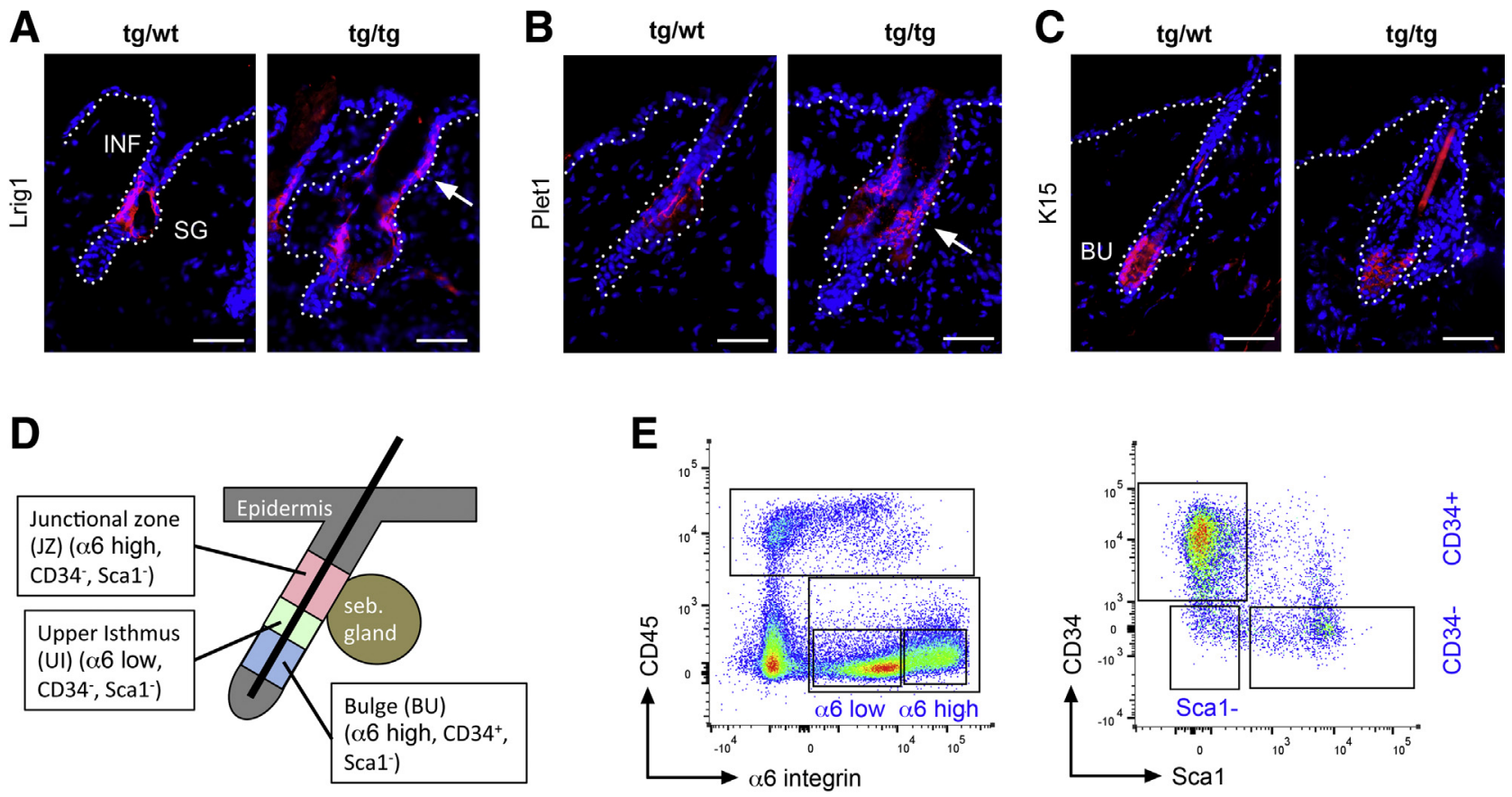

$\mathbf{F}$

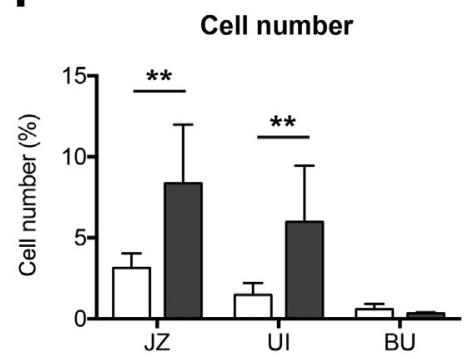

G

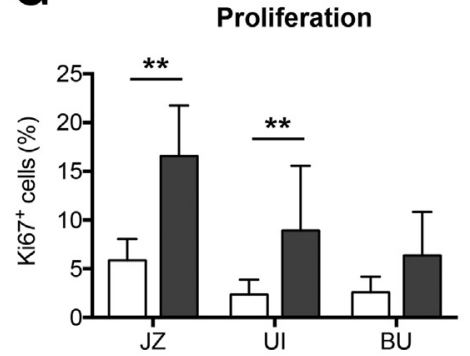

H

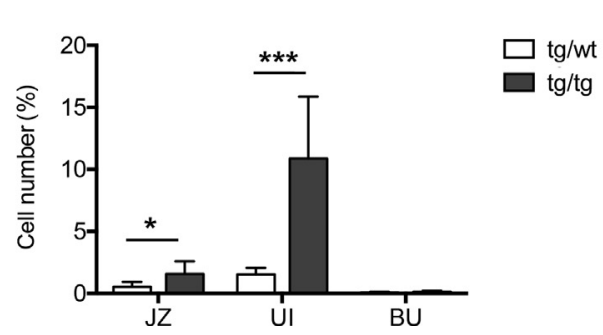

Figure 5 Expansion of cells expressing pilosebaceous stem cell markers in K5cre-CMVcaNrf2 mice. Immunofluorescence for Lrig1 (A), Plet-1 (B), and K15 (C) using sections of $\mathrm{tg} / \mathrm{wt}$ and $\mathrm{tg} / \mathrm{tg}$ back skin. The dotted lines demarcate the basement membrane. The arrows indicate strong expression of Lrig1 (A) and Plet1 (B) in the hair follicles (HF) of $\mathrm{tg} / \mathrm{tg}$ mice. D: Schematic representation of stem cell populations in murine HF and corresponding markers used for flow cytometry. E: Gating strategy used for analysis-CD45 and $\alpha_{6}$-integrin (left panel), followed by CD34 and Sca1 (right panel). F-H: Cell number (F) and proliferation (Ki-67-positive cells) (G) of cells expressing markers of junctional zone (JZ), upper isthmus (UI), and bulge (BU) stem cells in the back skin of $\mathrm{tg} / \mathrm{wt}$ and $\mathrm{tg} / \mathrm{tg}$ mice and cell number of the same cell populations in the periphery of 5-day wounds of $\mathrm{tg} / \mathrm{wt}$ and $\mathrm{tg} / \mathrm{tg}$ mice as analyzed by flow cytometry (H). $n=6$ to 7 . ${ }^{*} P \leq 0.05,{ }^{*} P \leq 0.01$, and ${ }^{* *} P \leq 0.001$ (U-test). Scale bar $=50 \mu \mathrm{m}$. INF, infundibulum; SG, sebaceous gland.

\section{Nrf2 Activation Does Not Directly Affect the Wound Epidermis}

A possible mechanism underlying the increased number of keratinocytes seen in the wound epithelium of K5creCMVcaNrf2 mice is a higher rate of cell proliferation in this area of the wound. This assumption was based on the increased keratinocyte proliferation observed in the nonwounded epidermis of these mice, which is a consequence of epidermal barrier disturbance, inflammation, and up-regulation of keratinocyte mitogens. ${ }^{20}$ However, contrary to nonwounded skin, there was no increase in the rate of proliferation in the wound epithelium of $\mathrm{tg} / \mathrm{tg}$ compared with $\mathrm{tg} / \mathrm{wt}$ mice at days 1,3 , and 5 after injury (Figure 2A). TEWL, a read-out for inside-out barrier functionality, was not elevated but rather mildly reduced in these wounds, most likely reflecting the faster healing (Figure 2B). The number of $\mathrm{T}$ lymphocytes was mildly but significantly increased in the granulation tissue of $\mathrm{tg} / \mathrm{tg}$ compared with $\mathrm{tg} / \mathrm{wt}$ mice (Figure 2C), whereas the opposite result was obtained for macrophages (Figure 2D). This finding may be a consequence of the accelerated healing because T-lymphocyte counts increase in wounded skin at a rather late stage of the repair process, ${ }^{24}$ concomitant with a decrease in macrophages. ${ }^{25}$ By contrast, no difference in the numbers of neutrophils and mast cells was observed (Figure 2, E and F). RT-qPCR analysis and immunohistochemistry revealed up-regulation of a key driver of the Nrf2-mediated barrier defect, small proline rich protein $2 \mathrm{~d}$ (Sprr2d), in the wound epidermis of control mice (Figure 2, $\mathrm{G}$ and $\mathrm{H})$. Sprr2d expression was increased in the nonwounded epidermis of $\mathrm{tg} / \mathrm{tg}$ mice as previously described ${ }^{20}$; however, it was not further up-regulated compared with tg/ wt mice on wounding (Figure 2, G and $\mathrm{H}$ ). The epidermal 
phenotype of K5cre-CMVcaNrf2 mice was reestablished 13 days after wounding, when an increase in both epidermal thickness and TEWL was observed (Supplemental Figure S2, A and B). This correlated with a gradual decrease in Sprr2d expression in control mice at day 7 after wounding; however, high expression of Sprr2d persisted in K5cre-CMVcaNrf2 mice (Supplemental Figure S2C). Expression of Nqol remained relatively constant throughout wound healing (Supplemental Figure S2D).

A
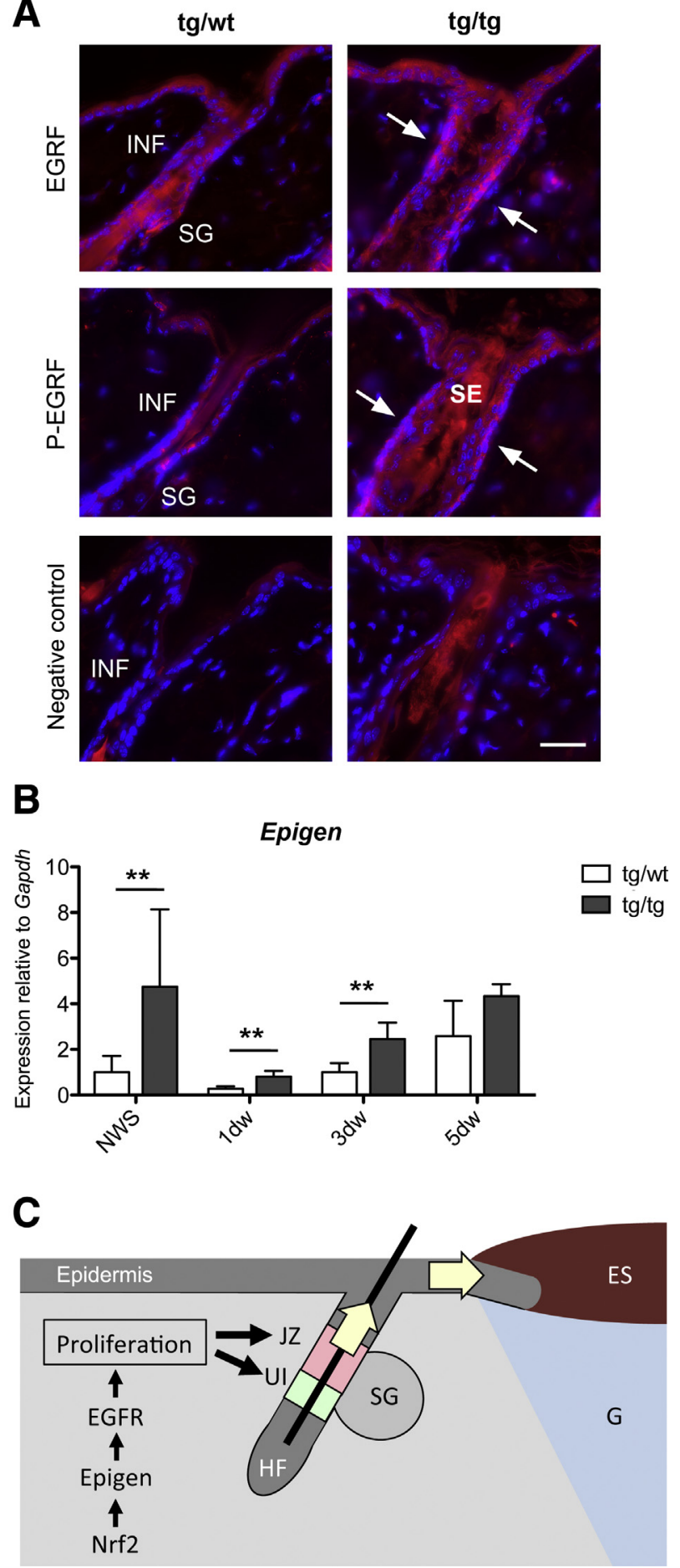

Because both TEWL and expression of Sprr2d were similar in wounds of mice of both genotypes, it seems unlikely that the barrier defect characteristic for nonwounded skin of $\mathrm{K} 5 \mathrm{cre}-\mathrm{CMV}$ caNrf2 mice is responsible for the increased number of keratinocytes in the wound epithelium.

It was recently reported that pharmacologic activation of Nrf2 enhanced wound closure in diabetic mice because of reduced apoptosis and enhanced migration of keratinocytes in the wound epithelium. ${ }^{17}$ In the nondiabetic mice, however, only a few apoptotic cells were present in the wound epithelium as revealed by immunofluorescence staining for cleaved caspase- 3 and by ultrastructural analysis, and this was not affected by the caNrf2 transgene (Figure 3A). Furthermore, scratch assays revealed no change in the rate of migration of immortalized mouse keratinocytes from wild-type mice on treatment with the Nrf2-activating compounds sulforaphane (Figure $3 \mathrm{~B}$ ) and no difference in the migration rate of murine primary keratinocytes from $\mathrm{tg} / \mathrm{tg}$ versus tg/wt mice, although Nrf2 target genes were significantly up-regulated (Figure 3, C and D). This finding was confirmed in a transwell migration assay, where no difference between vehicle and sulforaphane-treated keratinocytes was detected (Figure 3E). Finally, the differentiation markers keratin 10 and loricrin were normally expressed in the hyperproliferative epithelium (Figure 3, F-H). Taken together, these data suggest that Nrf2 activation does not directly influence proliferation, differentiation, apoptosis, or migration of keratinocytes in the wound epithelium.

\section{Genetic Nrf2 Activation Enhances Re-Epithelialization by Promoting Proliferation of Cells in the Pilosebaceous Unit}

Because a direct effect of Nrf2 activation on the wound epithelium was ruled out, the potential involvement of HFs in the wound periphery of $\mathrm{K} 5 \mathrm{cre}-\mathrm{CMV}$ caNrf2 mice was analyzed. HFs peripheral to wounds of K5cre-CMVcaNrf2 mice were notably enlarged and exhibited hyperproliferation and expression of keratin 6 (Figure 4, A-D), a HF keratin that is also expressed in hyperproliferative interfollicular keratinocytes. ${ }^{26}$ To assess the functional consequence of

Figure 6 Epigen is a possible mediator of the expansion of pilosebaceous stem cells. A: Immunofluorescence for epidermal growth factor receptor (EGFR; top row), phosphorylated EGFR (pEGFR) (middle row), and negative control (no primary antibody; bottom row) in $\mathrm{tg} / \mathrm{wt}$ and $\mathrm{tg} / \mathrm{tg}$ mice. Arrows depict stronger immunofluorescence signal for EGFR/pEGFR in the infundibulum (INF) of $\mathrm{tg} / \mathrm{tg}$ mice. B: Quantitative RT-PCR analysis for Epgn relative to Gapdh using RNA from epidermis of nonwounded skin (NWS) and 1-day wound (1dw), 3dw, and $5 \mathrm{dw}$ of $\mathrm{tg} / \mathrm{wt}$ and $\mathrm{tg} / \mathrm{tg}$ mice. Mean values of nonwounded epidermis of $\mathrm{tg} / \mathrm{wt}$ mice were arbitrarily set to 1. C: Working model: nuclear factor (erythroid-derived 2)-like 2 (Nrf2) activation stimulates proliferation of junctional zone (JZ) and upper isthmus (UI) pilosebaceous stem cells by epigen-mediated EGFR signaling. This enhances the pool of pilosebaceous stem cell-derived keratinocytes that migrate into the wound, leading to faster wound closure. $n=4$ to 7 . ${ }^{* *} P \leq 0.01$ (U-test). Scale bar $=50 \mu \mathrm{m}$. ES, eschar; $\mathrm{G}$, granulation tissue; $\mathrm{HF}$, hair follicle; SE, sebum; SG, sebaceous gland. 
these HF abnormalities, the healing of abrasion wounds was studied in K5cre-CMVcaNrf2 mice. In this model, differentiated keratinocytes are removed mechanically by tape stripping, and a hyperproliferative epithelium is formed underneath the resulting scab by keratinocytes that originate from the HFs below the surface of the denuded interfollicular epidermis (Figure 4E). ${ }^{26}$ Although the interfollicular distance was relatively constant across genotypes (Figure 4F), K5cre-CMVcaNrf2 mice exhibited faster wound closure, mediated through the formation of a longer outgrowth with a larger number of cells from HFs in the abraded area (Figure 4, G-I).

To gain further insight into the mechanisms underlying the effect of activated Nrf2 on the pilosebaceous unit, the cells were analyzed for expression of markers characteristic of follicular stem cell populations. Immunofluorescence

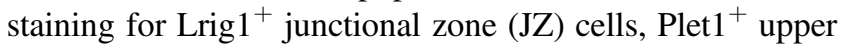
isthmus (UI) cells, and cytokeratin $15^{+}$bulge (BU) cells $^{27-29}$ showed a selective expansion of the JZ and UI pilosebaceous stem cell populations in $\mathrm{tg} / \mathrm{tg}$ mice, whereas BU stem cells were normal (Figure 5, A-C). Flow cytometry using antibodies against markers for BU cells $\left(\mathrm{CD} 45^{-} \mathrm{CD} 49 \mathrm{f}^{\mathrm{hi}} \mathrm{Sca} 1^{-} \mathrm{CD} 34^{+}\right)$, $\mathrm{JZ}$ cells $\left(\mathrm{CD} 45^{-} \mathrm{CD} 49 \mathrm{f}^{\mathrm{hi}}\right.$ $\mathrm{Sca1}^{-} \mathrm{CD} 34^{-}$cells), and UI cells $\left(\mathrm{CD} 45^{-} \mathrm{CD} 49 \mathrm{f}^{\text {lo }} \mathrm{Sca}^{-}\right.$ $\left.\mathrm{CD}^{-} 4^{-}\right)^{27}$ (Figure 5, D and E) confirmed a strong increase in the number of pilosebaceous cells expressing JZ and UI stem cell markers, whereas cells expressing BU markers were only mildly affected (Figure 5F). Furthermore, the proliferation rate of cells positive for JZ and UI cell markers was significantly increased (Figure 5G). Expansion of these cells was also observed in the periphery of 5-day wounds (Figure 5H).

\section{Epigen Is a Possible Mediator of Nrf2-Induced Pilosebaceous Cell Expansion}

The gene that encodes epigen has recently been identified as a direct target of Nrf2, and it is broadly expressed in the HFs of K5cre-CMVcaNrf2 mice. ${ }^{21}$ Immunofluorescence analysis revealed a more intense staining for total and phosphorylated (activated) epidermal growth factor receptor (EGFR), the high affinity receptor for epigen, in the infundibula of K5cre-CMVcaNrf2 mice, indicating activation of the EGFR pathway (Figure 6A). Interestingly, transgenic mice with inducible expression of epigen in keratinocytes also exhibited a thicker HF infundibulum and larger sebaceous glands, which was mediated through an expansion of both the JZ and UI stem cell populations. ${ }^{30}$ Because the phenotype of these mice phenocopies the abnormalities seen in K5cre-CMVcaNrf2 mice, epigen-mediated stimulation of JZ and UI stem cells proliferation via the EGFR pathway provides a possible explanation for the hyperplasia of the infundibula and sebaceous glands in the latter. Consistent with this assumption, the up-regulation of epigen was maintained in the wound epithelium of 1-, 3-, and 5-day wounds of K5cre-CMVcaNrf2 mice (Figure 6B). These data suggest that Nrf2 activation increases the pool of JZ and UI stem cells at least in part via up-regulation of epigen and consequent EGFR-stimulated cell proliferation. This larger pool of cells peripheral to the wound forms a longer wound epithelium, leading to enhanced wound closure (Figure 6C).

\section{Discussion}

We found that activation of Nrf2 in keratinocytes accelerates wound repair through activation of cells of the pilosebaceous unit in the wound periphery. The expansion of this cell population provides a large pool of keratinocytes that contribute to wound reepithelialization, thereby promoting wound closure. By contrast, Nrf2 activation did not promote proliferation of cells in the wound epithelium or migration of keratinocytes in vitro, and there was also no major effect on the wound inflammatory response. Furthermore, despite the barrier function deficit of K5creCMVcaNrf2 mice in nonwounded skin, repair of the barrier in the wound proceeded normally in these mice. Mice of both genotypes exhibited equally high expression levels of Sprr2d, a main driver of the barrier defect in K5cre-CMVcaNrf2 mice, in the wound epithelium. Sprr proteins are ROS scavengers and thus required for efficient protection from ROS damage. ${ }^{31}$ Their expression is regulated by several other proteins, such as activator protein 1 , E26 transformation specific, and octamer transcription factors. ${ }^{32}$ The combined action of these factors is likely to result in the strong up-regulation of Sprr2d in the wound epithelium that cannot be further promoted by Nrf2 activation.

At the periphery of the wound and in the migratory wound tongue, keratinocytes come into close contact with ROS-producing immune cells. Low levels of ROS stimulate the migration and proliferation of neighboring keratinocytes, whereas high levels are deleterious and induce apoptosis. $^{14,33,34}$ In diabetic mice, pharmacologic Nrf2 activation or Keap1 knockdown enhanced wound healing through reduction of oxidative damage, thereby protecting keratinocytes in the wound epithelium from apoptosis. ${ }^{17-19}$ However, in the nondiabetic wound model, no obvious signs of apoptosis or any other form of cell death were detected in the wound epithelium, indicating that ROS levels are not sufficiently high to induce significant cell death. Together with the normal migration and proliferation of keratinocytes, this finding suggests that ROS modulation by Nrf2 activation is most likely not the primary mechanism responsible for the presence of a longer wound epithelium in K5cre-CMVcaNrf2 mice.

Immediately after wounding, keratinocytes at the wound edge begin to migrate into the wound to form the wound epithelium. This migration requires the activation and proliferation of keratinocyte stem cell populations in the interfollicular epidermis and in the pilosebaceous unit 
adjacent to the wound. Lineage tracing experiments had found that cells derived from all three pilosebaceous stem cell populations (BU, UI, and JZ) migrate into the wound and contribute to the formation of the wound epithelium. ${ }^{35-37}$ In K5cre-CMVcaNrf2 mice, an increase in the proliferation of follicular cells and a significantly thicker infundibulum were detected. In a tape stripping abrasion wound model where the wound epithelium is exclusively generated by migration of keratinocytes out of the remaining HFs, K5cre-CMVcaNrf2 mice had a longer wound epithelium. Furthermore, a significant expansion and enhanced proliferation of pilosebaceous cells with markers of UI and JZ stem cells, but not of BU stem cells, was observed. In nonwounded skin, BU stem cells generate the lower part of the $\mathrm{HF}$ and the hair during normal HF cycling, whereas JZ and UI stem cells together generate the upper part of the HF and sebaceous glands. ${ }^{27,37}$ The selective expansion of the latter in $\mathrm{K} 5 \mathrm{cre}$ CMVcaNrf2 mice provides a likely explanation for the increased thickness of the infundibula and sebaceous glands, whereas the thickness of the lower part of the HF was not affected. In addition, HF number, outgrowth, and hair cycle length were not altered in these mice. ${ }^{21}$ During wound healing, the expanded pool of pilosebaceous cells that expressed markers of UI and JZ stem cells provide a larger number of cells that contribute to reepithelialization.

The Nrf2-induced expansion of cells in the pilosebaceous unit may be explained at least in part by the up-regulation of the Nrf2 target epigen. Consistent with this assumption, treatment of K5cre-CMVcaNrf2 mice with the EGFR kinase inhibitor gefintinib ameliorated the phenotype. ${ }^{21}$ Furthermore, epigen-transgenic mice also exhibit a thicker infundibulum and larger sebaceous glands mediated through expansion of JZ and UI stem cell populations. ${ }^{30}$ The enhanced levels of epigen in these mice and in K5creCMVcaNrf2 mice are likely to result in EGFR pathway activation and consequent proliferation of these cells. It remains to be determined why Nrf2-mediated epigen expression selectively affects proliferation of cells in the upper pilosebaceous unit. Possible explanations are the particularly strong expression of epigen in the HF or local differences in the expression of other EGF or of EGFR family members.

The results reported here reveal a novel effect of activated $\mathrm{Nrf} 2$ in pilosebaceous cells on wound repair in healthy mice. Interestingly, the consequence of $\mathrm{Nrf} 2$ activation on the wound healing process is cell type-dependent. Although activation of Nrf2 in myeloid cells did not accelerate healing of full-thickness excisional wounds ${ }^{38} \mathrm{Nrf} 2$ activation in fibroblasts caused enhanced re-epithelialization through induction of fibroblast senescence and subsequent release of soluble factors that stimulate keratinocyte proliferation. ${ }^{39}$ Nrf2 activation or Keap1 knockdown at the wound site also promoted wound angiogenesis, indicating an additional effect of Nrf2 on endothelial cells. ${ }^{17-19}$ In the future, it will be interesting to determine whether pharmacologic Nrf2 activation at the wound edge also promotes wound closure by selective stimulation of UI and JZ stem cell proliferation and if this effect synergizes with other activities of Nrf2 at the wound site. In particular, it will be interesting to determine the effect of NRF2 activation in human wounds. Because most areas of human skin have fewer HFs compared with mouse skin, the effect of Nrf2 on the pilosebaceous unit observed in this study may only be relevant in areas of high HF density, such as scalp skin. By contrast, our previously demonstrated senescence-inducing effect of NRF2 activation was also seen with human fibroblasts and may thus be generally relevant for human wound healing. ${ }^{39}$ Therefore, transient and local NRF2 activation appears to be a promising approach to enhance the healing process in patients with wound healing disorders through activation of different healing promoting pathways.

\section{Acknowledgments}

We thank Andreas Bapst, Alessia Gravina, Andrina Stäubli, Jonas Schwestermann, Kevin Szillat, and Urs Wegmann (all previously with ETH Zurich) for invaluable experimental help; Drs. José Jorcano and Angel Ramirez for the K5-Cre mice. Dr. Beat Siegenthaler (ETH Zurich) for immortalized murine keratinocytes; Prof. Daniel Hohl, Université de Lausanne for the anti-Sprr antibody; Dr. Catherin Niemann (University of Cologne) for helpful suggestions; Dr. Christina Siemes-Rycken (previously with ETH Zurich) for help with the generation of mice and initial wound healing experiments; and the ETH Phenomics Center (Zurich, Switzerland) for mouse maintenance.

\section{Supplemental Data}

Supplemental material for this article can be found at https://doi.org/10.1016/j.ajpath.2018.11.017.

\section{References}

1. Schäfer M, Dütsch S, auf dem Keller U, Navid F, Schwarz A, Johnson DA, Johnson JA, Werner S: Nrf2 establishes a glutathionemediated gradient of UVB cytoprotection in the epidermis. Genes Dev 2010, 24:1045-1058

2. Lee Y, Shin JM, Jang S, Choi DK, Seo MS, Kim HR, Sohn KC, Im M, Seo YJ, Lee JH, Kim CD: Role of nuclear factor E2-related factor 2 (Nrf2) in epidermal differentiation. Arch Dermatol Res 2014, 306: 677-682

3. Schäfer M, Werner S: Nrf2-A regulator of keratinocyte redox signaling. Free Radic Biol Med 2015, 88:243-252

4. Xu C, Huang MT, Shen G, Yuan X, Lin W, Khor TO, Conney AH, Kong AN: Inhibition of 7,12-dimethylbenz(a)anthracene-induced skin tumorigenesis in C57BL/6 mice by sulforaphane is mediated by nuclear factor E2-related factor 2. Cancer Res 2006, 66:8293-8296

5. Kleszczynski K, Ernst IM, Wagner AE, Kruse N, Zillikens D, Rimbach G, Fischer TW: Sulforaphane and phenylethyl isothiocyanate protect human skin against UVR-induced oxidative stress and 
apoptosis: role of Nrf2-dependent gene expression and antioxidant enzymes. Pharmacol Res 2013, 78:28-40

6. Dinkova-Kostova AT, Jenkins SN, Fahey JW, Ye L, Wehage SL, Liby KT, Stephenson KK, Wade KL, Talalay P: Protection against UV-light-induced skin carcinogenesis in SKH-1 high-risk mice by sulforaphane-containing broccoli sprout extracts. Cancer Lett 2006, 240:243-252

7. Braun S, Hanselmann C, Gassmann MG, auf dem Keller U, BornBerclaz C, Chan K, Kan YW, Werner S: Nrf2 transcription factor, a novel target of keratinocyte growth factor action which regulates gene expression and inflammation in the healing skin wound. Mol Cell Biol 2002, 22:5492-5505

8. Moreira S, Stramer B, Evans I, Wood W, Martin P: Prioritization of competing damage and developmental signals by migrating macrophages in the Drosophila embryo. Curr Biol 2010, 20:464-470

9. Fu XJ, Peng YB, Hu YP, Shi YZ, Yao M, Zhang X: NADPH oxidase 1 and its derived reactive oxygen species mediated tissue injury and repair. Oxid Med Cell Longev 2014, 2014:282854

10. Niethammer P, Grabher C, Look AT, Mitchison TJ: A tissue-scale gradient of hydrogen peroxide mediates rapid wound detection in zebrafish. Nature 2009, 459:996-999

11. Dunnill C, Patton T, Brennan J, Barrett J, Dryden M, Cooke J, Leaper D, Georgopoulos NT: Reactive oxygen species (ROS) and wound healing: the functional role of ROS and emerging ROSmodulating technologies for augmentation of the healing process. Int Wound J 2017, 14:89-96

12. Schäfer M, Werner S: Oxidative stress in normal and impaired wound repair. Pharmacol Res 2008, 58:165-171

13. Roy S, Khanna S, Nallu K, Hunt TK, Sen CK: Dermal wound healing is subject to redox control. Mol Ther 2006, 13:211-220

14. O’Toole EA, Goel M, Woodley DT: Hydrogen peroxide inhibits human keratinocyte migration. Dermatol Surg 1996, 22:525-529

15. Sindrilaru A, Peters T, Wieschalka S, Baican C, Baican A, Peter H, Hainzl A, Schatz S, Qi Y, Schlecht A, Weiss JM, Wlaschek M, Sunderkotter C, Scharffetter-Kochanek K: An unrestrained proinflammatory M1 macrophage population induced by iron impairs wound healing in humans and mice. J Clin Invest 2011, 121:985-997

16. auf dem Keller U, Huber M, Beyer TA, Kumin A, Siemes C, Braun S, Bugnon P, Mitropoulos V, Johnson DA, Johnson JA, Hohl D, Werner S: Nrf transcription factors in keratinocytes are essential for skin tumor prevention but not for wound healing. Mol Cell Biol 2006, 26:3773-3784

17. Long M, Rojo de la Vega M, Wen Q, Bharara M, Jiang T, Zhang R, Zhou S, Wong PK, Wondrak GT, Zheng H, Zhang DD: An essential role of NRF2 in diabetic wound healing. Diabetes 2016, 65:780-793

18. Soares MA, Cohen OD, Low YC, Sartor RA, Ellison T, Anil U, Anzai L, Chang JB, Saadeh PB, Rabbani PS, Ceradini DJ: Restoration of Nrf2 signaling normalizes the regenerative niche. Diabetes 2016, 65:633-646

19. Rabbani PS, Zhou A, Borab ZM, Frezzo JA, Srivastava N, More HT, Rifkin WJ, David JA, Berens SJ, Chen R, Hameedi S, Junejo MH, Kim C, Sartor RA, Liu CF, Saadeh PB, Montclare JK, Ceradini DJ: Novel lipoproteoplex delivers Keap1 siRNA based gene therapy to accelerate diabetic wound healing. Biomaterials 2017, 132:1-15

20. Schäfer M, Farwanah H, Willrodt AH, Huebner AJ, Sandhoff K, Roop D, Hohl D, Bloch W, Werner S: Nrf2 links epidermal barrier function with antioxidant defense. EMBO Mol Med 2012, 4:362-379

21. Schäfer M, Willrodt AH, Kurinna S, Link AS, Farwanah H, Geusau A, Gruber F, Sorg O, Huebner AJ, Roop DR, Sandhoff K, Saurat JH, Tschachler E, Schneider MR, Langbein L, Bloch W, Beer HD, Werner S: Activation of Nrf2 in keratinocytes causes chloracne (MADISH)-like skin disease in mice. EMBO Mol Med 2014, 6:442-457

22. Rolfs F, Huber M, Kuehne A, Kramer S, Haertel E, Muzumdar S, Wagner J, Tanner Y, Bohm F, Smola S, Zamboni N, Levesque MP,
Dummer R, Beer HD, Hohl D, Werner S, Schäfer M: Nrf2 activation promotes keratinocyte survival during early skin carcinogenesis via metabolic alterations. Cancer Res 2015, 75:4817-4829

23. Yang J, Meyer M, Muller AK, Bohm F, Grose R, Dauwalder T, Verrey F, Kopf M, Partanen J, Bloch W, Ornitz DM, Werner S: Fibroblast growth factor receptors 1 and 2 in keratinocytes control the epidermal barrier and cutaneous homeostasis. J Cell Biol 2010, 188: 935-952

24. Chen L, Mehta ND, Zhao Y, DiPietro LA: Absence of CD4 or CD8 lymphocytes changes infiltration of inflammatory cells and profiles of cytokine expression in skin wounds, but does not impair healing. Exp Dermatol 2014, 23:189-194

25. Wood S, Jayaraman V, Huelsmann EJ, Bonish B, Burgad D, Sivaramakrishnan G, Qin S, DiPietro LA, Zloza A, Zhang C, Shafikhani SH: Pro-inflammatory chemokine CCL2 (MCP-1) promotes healing in diabetic wounds by restoring the macrophage response. PLoS One 2014, 9:e91574

26. Wojcik SM, Bundman DS, Roop DR: Delayed wound healing in keratin 6a knockout mice. Mol Cell Biol 2000, 20:5248-5255

27. Jensen KB, Collins CA, Nascimento E, Tan DW, Frye M, Itami S, Watt FM: Lrig1 expression defines a distinct multipotent stem cell population in mammalian epidermis. Cell Stem Cell 2009, 4:427-439

28. Liu Y, Lyle S, Yang Z, Cotsarelis G: Keratin 15 promoter targets putative epithelial stem cells in the hair follicle bulge. J Invest Dermatol 2003, 121:963-968

29. Raymond K, Richter A, Kreft M, Frijns E, Janssen H, Slijper M, Praetzel-Wunder S, Langbein L, Sonnenberg A: Expression of the orphan protein Plet-1 during trichilemmal differentiation of anagen hair follicles. J Invest Dermatol 2010, 130:1500-1513

30. Dahlhoff M, Frances D, Kloepper JE, Paus R, Schafer M, Niemann C, Schneider MR: Overexpression of epigen during embryonic development induces reversible, epidermal growth factor receptor-dependent sebaceous gland hyperplasia. Mol Cell Biol 2014, 34:3086-3095

31. Vermeij WP, Backendorf C: Skin cornification proteins provide global link between ROS detoxification and cell migration during wound healing. PLoS One 2010, 5:e11957

32. Patel S, Kartasova T, Segre JA: Mouse Sprr locus: a tandem array of coordinately regulated genes. Mamm Genome 2003, 14:140-148

33. Loo AE, Ho R, Halliwell B: Mechanism of hydrogen peroxide-induced keratinocyte migration in a scratch-wound model. Free Radic Biol Med 2011, 51:884-892

34. Lisse TS, Rieger S: IKKalpha regulates human keratinocyte migration through surveillance of the redox environment. J Cell Sci 2017, 130: 975-988

35. Page ME, Lombard P, Ng F, Gottgens B, Jensen KB: The epidermis comprises autonomous compartments maintained by distinct stem cell populations. Cell Stem Cell 2013, 13:471-482

36. Snippert HJ, Haegebarth A, Kasper M, Jaks V, van Es JH, Barker N, van de Wetering M, van den Born M, Begthel H, Vries RG, Stange DE, Toftgard R, Clevers H: Lgr6 marks stem cells in the hair follicle that generate all cell lineages of the skin. Science 2010, 327:1385-1389

37. Ito $\mathrm{M}$, Liu $\mathrm{Y}$, Yang $\mathrm{Z}$, Nguyen J, Liang F, Morris RJ, Cotsarelis G: Stem cells in the hair follicle bulge contribute to wound repair but not to homeostasis of the epidermis. Nat Med 2005, 11:1351-1354

38. Joshi N, Werner S: Nrf2 is highly expressed in neutrophils, but myeloid cell-derived Nrf2 is dispensable for wound healing in mice. PLoS One 2017, 12:e0187162

39. Hiebert P, Wietecha MS, Cangkrama M, Haertel E, Mavrogonatou E, Stumpe M, Steenbock H, Grossi S, Beer HD, Angel P, Brinckmann J, Kletsas D, Dengjel J, Werner S: Nrf2-mediated fibroblast reprogramming drives cellular senescence by targeting the matrisome. Dev Cell 2018, 46:145-161.e10 